\title{
Antropologia, arte e compartilhamento de saberes sobre a cidade: encontros, caminhadas e produção audiovisual em projeto de pesquisa e extensão universitária
}

\author{
Caterine Reginensi ${ }^{1}$ \\ Lilian Sagio Cezar ${ }^{2}$ \\ Julia Dias Pereira ${ }^{3}$
}

Resumo

Neste artigo as autoras descrevem e analisam o processo de pesquisa desenvolvido a partir de metodologias qualitativas e participativas envolvendo performances e produção audiovisual com jovens integrantes do grupo de teatro Oriundo em articulação ao Projeto de Pesquisa e Extensão AntropoArte (2017 e 2018), numa favela da cidade de Campos dos Goytacazes, RJ. O processo de pesquisa articula o campo da antropologia, produção audiovisual e arte para discutir com os interlocutores o acesso desigual à cidade e o processo complexo de mudança que alguns desses jovens e suas famílias vivenciaram ao serem removidos da favela Margem da Linha para o programa habitacional "Morar Feliz". Esses temas foram abordados por meio da proposição dialógica de performances, caminhadas fotográficas, produção de árvores genealógicas e entrevistas com jovens e seus familiares, materiais sistematizados a partir da produção de um filme e das ações desenvolvidas pelo grupo teatral que permitiram abordar possíveis contribuições da antropologia à extensão universitária, debatendo os significados que os interlocutores, em sua maioria jovens negros, dão as suas ações e referências estéticas.

Palavras-chave: antropologia visual; metodologia de pesquisa qualitativa; extensão universitária; educação.

Anthropology, art and knowledge sharing about the city: encounters, walks and audiovisual production in a research project and university extension

\section{Abstract}

In this article, the authors describe and analyze the research process developed from qualitative and participatory methodologies involving performances and audiovisual production with young members of the Oriundo theater group in conjunction with the AntropoArte University Research and Extension Project (2017 and 2018), in a slum in the city of Campos dos Goytacazes, RJ. The research process articulates the field of anthropology, audiovisual production and art to discuss with the interlocutors the unequal access to the city and the complex process of change that some of these young people and their families experienced when they were removed from the Margem da Linha favela for the housing

1 Programa de Pós-Graduação em Políticas Sociais, Programa de Pós-Graduação em Sociologia Política, Universidade Estadual do Norte Fluminense Darcy Ribeiro, UENF.

2 Programa de Pós-Graduação em Políticas Sociais, Universidade Estadual do Norte Fluminense Darcy Ribeiro, UENF.

3 Programa de Pós-Graduação em Políticas Sociais (Mestrado), Universidade Estadual do Norte Fluminense Darcy Ribeiro, UENF. 
program. "Morar Feliz". These themes were addressed through the dialogical proposition of performances, photographic walks, production of family trees and interviews with young people and their families, materials systematized from the production of film and the actions developed by the theatrical group that allowed to address possible contributions from anthropology to university extension, debating the meanings that the interlocutors, mostly young blacks, give their actions and aesthetic references.

Keywords: visual anthropology; qualitative research methodology; University Extension; education

\section{Introdução}

Esse artigo é resultado de múltiplos encontros e se esforça para narrar, à seis mãos, os pontos comuns sob os quais cada uma das autoras assumem reflexivos pontos de vistas sobre o processo de construção audiovisual agenciado em empreendimentos etnográficos. Para tanto, nos propomos a refletir sobre o processo de construção do filme "Caminhadas e Encontros - Da Margem da Linha à Tapera III"4 e o diálogo constante entre a antropóloga-diretora e as demais pesquisadoras aqui reunidas para o empreendimento coletivo de escrita e análise, sob diferentes prismas, da produção imagética dessa pesquisa.

Abordamos os resultados dessa investigação a partir do ponto de vista dos interlocutores, por meio da análise do processo de construção de diálogos pautados na produção de performances, fotografias, vídeos, mapas falados e árvores genealógicas que foram sendo retroalimentados ao longo de dois anos de pesquisa, pelo próprio processo de devolução dos materiais sistematizados, editados e impressos em diferentes suportes, materialidades, estas que nos permitem refletir mais detidamente sobre como colocar os saberes e conhecimentos antropologicamente produzidos a disposição de nossos interlocutores?

Como base para as discussões, buscamos ponderar questões enunciadas por Reginensi:

A busca de agenciamentos (DELEUZE e GUATTARI, 1980) traz permanentemente um repertório de questões: o que é escrever? O que fotografar e filmar com a experiência do outro? Não existem fórmulas nem respostas definitivas a partir dessa experiência curta, incompleta, insuficiente. $\mathrm{O}$ mais importante é a relação que se estabelece entre diferentes vozes que contam histórias. (2019, p.193)

Desde o início, esse trabalho esteve pautado nos princípios da extensão universitária que compreende a pesquisa enquanto processo de construção, troca e compartilhamento de experiências e conhecimentos, que nesse caso aconteceram a partir da produção de diferentes tipos de imagens (fotografia, vídeo, grafite, desenhos, mapas) e três performances teatrais (denominadas de "Poisson"; "Olhares de jovens sobre um lugar chamado Margem da Linha" e "Encontros") de modo que optou-se por procedimentos de pesquisa antropológica com imagens (Nichols, 1997), o que é muito distinto de se construir formas de representação imagética de qualquer discurso científico previamente concebido.

A busca experimental e metodológica exigidas pela própria antropologia está pautada no trabalho de campo com observação participante, por meio do qual se constrói a composição de um horizonte ético positivo, o compartilhar de diálogos, saberes e visões de mundo e o ato de distanciamento engajado que permite a representação de uma dada cultura, ainda que aconteça por meio da produção e compartilhamento de imagens.

Partindo do reconhecimento de que os processos de produção de imagem tendem a ser eminentemente coletivos pois, em geral, envolvem um ou mais produtores e seu(s) receptor(es), nos pautamos nas imagens resultantes da própria pesquisa buscando tensionar a diversidade de 
miradas possíveis de serem exploradas, a partir de um entrecruzar de matrizes (oral, escrita, gráfica, imagética, performática) envolvendo preocupações, experiências e afetos (FRAVETSAADA, 2007), em que o filme etnográfico constitui momento de construção e troca, devolutiva e retroalimentação de saberes e sentidos que os próprios interlocutores, a maioria jovens negros e seus familiares, conferem às suas ações e referências estéticas.

O processo de pesquisa e produção audiovisual acontece articulado a um projeto social que desenvolve ações de educação nãoformal, fora da escola, ainda que na sede do Centro Juvenil São Pedro, como também na Universidade Estadual do Norte Fluminense Darcy Ribeiro (UENF) ou em espaços de ações coletivas e cotidianas como as ruas das comunidades Margem da Linha e Tapera III, a partir da troca de experiências e saberes entre todos os envolvidos que são estimulados a assumir o protagonismo diante de seu próprio processo de aprendizagem.

No plano da macroanálise, os dados gerais dos Mapas da Violência no Brasil (20162019) informam que o município de Campos dos Goytacazes figura entre as cidades com altas taxas de homicídio do país, números que no Brasil revelam a face cruel do massacre da população jovem e negra ${ }^{5}$. Focalizar as possíveis contribuições de pesquisas antropológicas articuladas às ações de extensão universitária para o desenvolvimento e ampliação do escopo da educação não-formal nos permite re-conhecer ações que potencializem a aplicação das Leis $10.639 / 2003$ e 11.645/20082, questionando como a antropologia e seus referenciais teóricometodológicos podem contribuir para que as culturas locais, os conhecimentos e visões de mundo de crianças, jovens e seus familiares possam ser pautados em diálogos simétricos nos processos educativos, projetando assim a autonomia e protagonismo de seus agentes visando a construção de uma sociedade digna e pacífica?

Optamos por organizar o artigo em cinco partes que, inspiradas na estrutura teatral, denominamos de Atos. Assim, o artigo é constituído por cinco Atos que revelam os bastidores da etnografia/arte, os encontros e caminhadas nas margens da cidade, a produção imagética do projeto AntropoArte, a construção do filme-documentário "Caminhadas e encontros da Margem da Linha a Tapera III e aspectos da produção audiovisual, pensando a pesquisa e extensão universitária enquanto meio de experimentar e potencializar práticas de educação não-formal.

\section{Ato 1: Encontros nas margens}

Quem diria que uma antropóloga francesa viria morar no Brasil e se encontraria com uma antropóloga caipira, quando ambas, atraídas pela carreira universitária, passariam a produzir outros encontros em meio ao cultivo artesanal de sonhos acadêmicos? E, que essas professoras-pesquisadoras se engajariam na formação de uma nova geração de antropólogas (os), aqui representada por uma mestranda, estando esses encontros pautados na produção imagética enquanto recurso metodológico em pesquisa qualitativa? Pois foi desse encontro de experiências, sotaques, engenhosidades e generosidades em relação às ações desenvolvidas na universidade, na área de antropologia, que permitiram que perspectivas distintas pudessem ser articuladas. Assim, esse texto é resultado desse e de outros encontros, inicialmente da pesquisadora com o Centro Juvenil São Pedro, em especial, com a professora Jovana e seus alunos.

Em março de 2017, a professora Caterine Reginensi pesquisadora teve aprovado o projeto de pesquisa e extensão universitária AntropoArte junto aos editais de fomento da Pró-Reitoria

5 Segundo o Atlas da Violência no Brasil o país teve em 2016 o total de 62.517 assassinatos cometidos, desses 71,5\% das pessoas assassinadas são negras ou pardas. Homens jovens, entre 15 e 29 anos, representam 53,7\% das vítimas totais no país (ou seja, 33.590 óbitos). 
de Extensão e Assuntos Comunitários - UENF 6 e passou a atuar assiduamente junto ao grupo teatral Oriundo. Esse processo inicial gerou a construção conjunta da performance denominada Poisson (em Português significa Peixe) composto a partir da poesia homônima de Paul Eluard e, a partir dela, os jovens do Oriundo abordaram em forma de performance sua relação com a água, dramatizando situações vivenciadas no cotidiano da comunidade da Margem da Linha em decorrência dos problemas enfrentados a partir dos constantes alagamentos. Foi assim que a pesquisadora apresentou sua colega antropóloga aos jovens do Oriundo e à professora Jovana, para compartilhar experiências na produção fotográfica e audiovisual junto às ações do AntropoArte.

Oriundo $^{7}$ é o nome do grupo de teatro formado pela atriz amadora e animadora cultural Jovana Patrícia da Hora Barcelos ${ }^{8}$ que congrega jovens de 12 a 21 anos a partir de processos de educação não-formal, tendo como ponto de partida o projeto social do Centro Juvenil São Pedro 9 , mantido por Salesianos na favela da Margem da Linha. Tais experiências teatrais tiveram como base e inspiração as ações do histórico Teatro Experimental do Negro (TEN) em que o ator e teatrólogo Abdias do Nascimento desenvolveu espaço alternativo de educação pautado em metodologias participativas e performáticas que focalizam o desenvolvimento do protagonismo negro na sociedade brasileira a partir da década de 1940, marcadamente racista e classista. $\mathrm{Na}$ experiência do TEN o teatro foi compreendido e vivenciado como arena de possibilidade de aprendizado, alfabetização, reconhecimento, visibilização, resistência política e econômica para a população negra. Esses princípios também podem ser observados na atuação do grupo teatral Oriundo que recebeu de braços abertos a professora francesa em suas atividades, inicialmente como observadora, mas já visando o planejamento de uma ação de pesquisa e extensão universitária.

Tivemos a oportunidade de construir dialogicamente a proposição da utilização de instrumentos metodológicos de pesquisa qualitativa junto ao grupo teatral para retroalimentar o próprio processo de criação da performance. Assim, após a experiência de filmagem de um dos ensaios do grupo propusemos a realização de uma caminhada em que a câmera fotográfica digital foi disponibilizada e compartilhada com nossos interlocutores e, a cada novo ângulo tomado em imagem, o grupo se reunia para visualizar o resultado na tela o que gerava comentários sobre a própria imagem e seus aspectos técnicos (foco, luz, enquadramentos etc.), o tema representado em imagem e sobre o próprio lugar em que caminhávamos conjuntamente.

A fachada do Centro Juvenil, a linha de trem desativada ladeada pela rua de paralelepípedo por onde as casas da comunidade foram sendo construídas e, pelo lado de trás, um grande e extenso muro feito de blocos de cimento que acompanha a linha de trem até o seu cruzamento com a estrada BR101. As crianças

6 Agradecemos à Faperj, Capes e CNPq pelo acesso a diferentes modalidades de financiamentos que contribuíram para a realização desse artigo. Agradecemos às bolsistas de extensão, graduandas de Ciências Sociais - UENF, Gabriela Viana de Lima, Paolla Corrêa Azeredo e Laís de Souza Teixeira e aos bolsistas de universidade-aberta Douglas Moreira Barros, graduando em Arquitetura e Urbanismo pelo IFF, Giovana Gomes Monteiro, atriz e moradora da própria comunidade e a professora de teatro Jovana Patrícia de Hora Barcelos pela dedicação ao projeto AntropoArte.

$7 \mathrm{Na}$ língua Portuguesa o adjetivo “oriundo" qualifica aquilo que se remete a origem, descendência, proveniência. Etimologicamente, essa palavra guarda raízes no conceito Ori (ou Ory), palavra que em Yorubá se remete às dimensões e matizes locais e familiares traduzidas em elementos religiosos, culturais e paradigmáticos adjacentes.

8 Jovana construiu trajetória artística no teatro amador de Campos, sendo tributária da "Geração do Teatro de Bolso e seus espaços de sociabilidade política nos anos 1980” (Matias, 2016), das atividades do Teatro Escola de Cultura Dramática que, posteriormente, geraram o Grupo Experimental do SESC.

9 Jovens que participam das atividades do Centro Juvenil ao completar 18 anos são desligados e deixam de ter permissão de acesso às dependências e ações ali desenvolvidas devido a alegadas questões burocráticas de autorização para o próprio funcionamento do Centro. Assim, o grupo de Teatro Oriundo, por sua identidade fluida permite que ex-alunos do Centro Juvenil continuem participando das ações e performances produzidas anualmente. 
e árvores da vizinhança, o gato sobre o muro, a birosca que encontramos do outro lado da travessia da BR 101, a estrutura em concreto do que deveria ser uma passarela, mas que está há tempos abandonada ao lado da estrada, uma outra obra de um prédio também abandonado tendo ao fundo o maior shopping center da cidade. Encontramos o muro de trás da antiga garagem da estrada de ferro e retivemos todas essas imagens a partir da atenção dos jovens traduzida em fotografias. Como também tínhamos em mente a construção da performance passamos a tematizar a água ao mesmo tempo que sentíamos algumas gotículas de chuva caindo por sobre nossas cabeças. Paramos na frente de um dos bueiros da extensa rua e fotografamos. Os comentários que se seguiram foram reveladores dos processos vividos por essas famílias em seu cotidiano.

A rua de paralelepípedos por onde foram construídas as casas que constituem a Margem da Linha estão no nível mais baixo quando comparado à própria linha de trem, o que demanda uma constante manutenção dos bueiros ali instalados, serviço que deveria ser regularmente prestado pelo poder público, mas que, de acordo com jovens, deixou de acontecer há algum tempo apesar do crescimento da região por conta dos grandes empreendimentos imobiliários de condomínios de alto padrão. Essa falta de limpeza dos bueiros faz com que as anuais chuvas de novembro a março provoquem constantes inundações das residências, situação agravada pela falta de saneamento básico e instalação da rede de coleta de esgoto nas casas da comunidade. Para minimizar os danos as famílias constroem fossas sépticas, mas, ao longo do período chuvoso, é recorrente a inundação da rua e das residências, provocando assim a contaminação do solo que se torna impróprio, principalmente para o plantio e criação de pequenos animais nos quintais, fator de vulnerabilidade ambiental dessa população majoritariamente pobre e negra. Dois dos rapazes do grupo nos relataram que o primeiro trabalho feito por eles que lhes rendeu pagamento em dinheiro tinha sido a abertura do grande e profundo buraco para a construção de fossa ali na vizinhança.

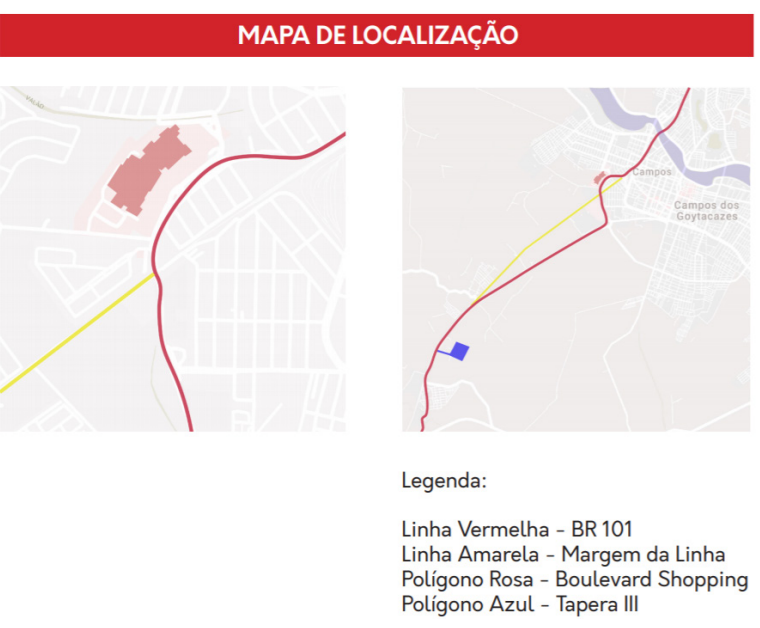

Figura 1. Mapa de localização da favela da Margem da linha (fonte: AntropoArte, Caderno digital, 06/2019).

\section{Ato 2: Caminhar pelas margens}

Andar e pensar um pouco, que só sei pensar andando. Três passos, e minhas pernas já estão pensando. Aonde vão dar estes passos? Acima, abaixo? Além? Ou acaso se desfazem ao mínimo vento sem deixar nenhum traço? (LEMINSKI, 1991)

Este poema de Leminski serve para introduzir uma reflexão não apenas sobre o ato de caminhar, mas sobretudo sobre a experiência de caminhar juntos nos espaços do cotidiano de jovens moradores da favela da Margem da Linha, permitindo refletir sobre a experiência de remoção para uma nova casa, em que passaram a habitar no bairro periférico da Tapera III. Esses jovens, que nos acompanham em percursos etnográficos, praticam performance teatral no grupo Oriundo e em suas criações, em particular, na última performance denominada Encontros, pautaram a figura de artistas caminhantes, produzida originalmente por Hélio Oiticica. 
Assim, a performance constituiu uma espécie de espelho de si mesmo, permitindo aos jovens a possibilidade de se tornar observadores de seus espaços de moradia e de vida, percebendo as implicações na produção e partilha de uma experiência sensível (RANCIÈRE, 2005) da cidade. Por partilha, Rancière compreende tanto:

a participação em um conjunto comum e, inversamente, a separação, a distribuição em quinhões. Uma partilha do sensível é, portanto, o modo como se determina no sensível a relação entre um conjunto comum partilhado e a divisão de partes exclusivas. (2005, p.7)

A cidade como um espaço sensível nos leva a reconsiderar a relação dialética que une a sociedade ao espaço, e, mais amplamente, o papel de atores múltiplos na transformação dos espaços urbanos que não são apenas prédios, caminhos, lugares, mas ambientes habitados, sensibilidade essa que só pode ser alcançada a partir do próprio contato direto de seus habitantes com a cidade e as ruas que frequentam no cotidiano (CERTEAU, 1994).

A ideia não é nova. Segundo Paola Jacques, caminhando pela cidade o flâneur percebe que "com a dita modernização, os mais pobres, são expulsos do centro de Paris (...), vão sendo 'varridos' das ruas, passam a ser figuras em extinção como suas antigas ruas e casas" (2003, p. 54). Jacques (2014) se reporta ao flâneur enquanto metáfora para analisar a trajetória de Hélio Oiticica em sua chegada no morro da Mangueira, cidade do Rio de Janeiro, deslocando-se de seu espaço comum para realizar um encontro de afetos e experiências, implicar-se na construção da comunidade, e só assim perceber a potência estética desse lugar que aos poucos lhe transformava, e lhe permitia a criação de obras artísticas. Oiticica, desse modo, penetrando na favela, não mais a partir da flanerie, transportando para a sua experiência o Outro que ele encontrou nessa troca, tornando-se também outro. Foi a partir das suas caminhadas, do seu contato mais profundo com a periferia do Rio de Janeiro e com o samba carioca que o artista conseguiu deslocar, não somente a sua produção artística, mas a sua própria visão de mundo, cada vez menos separada da arte.
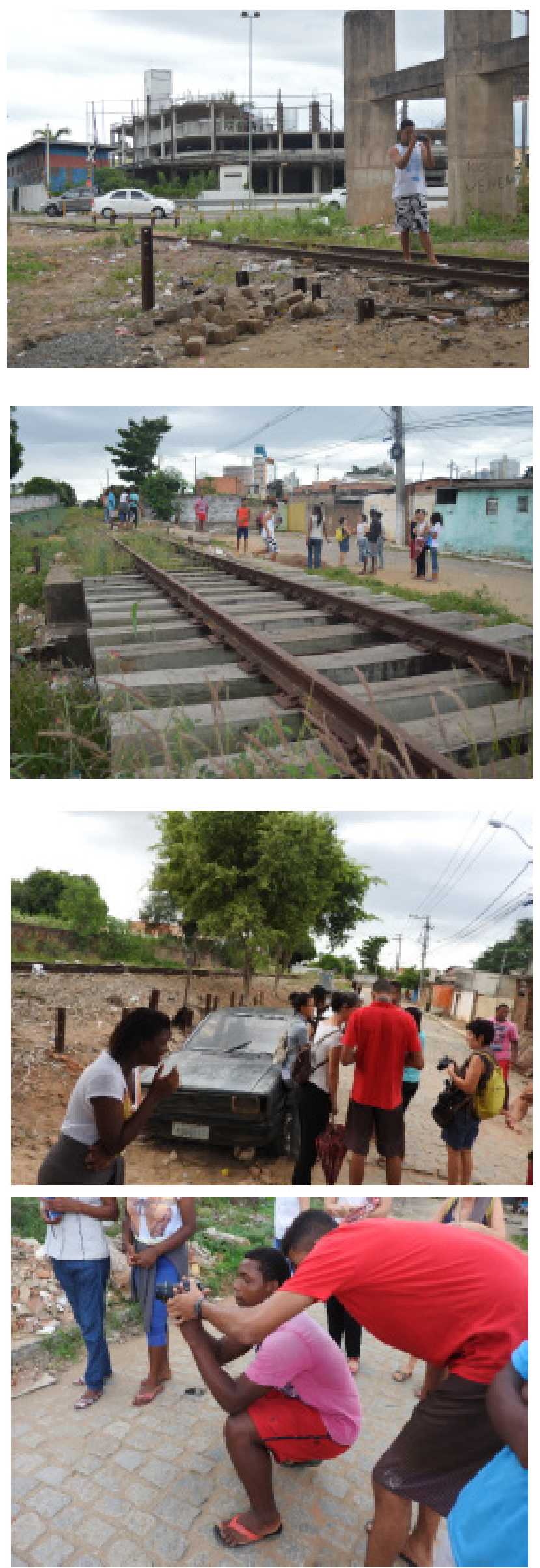
Figuras 2, 3, 4, 5. Fotografias realizadas a partir da ação dos jovens do grupo teatral Oriundo que compartilharam a experiência de caminhar e fotografar na Margem da Linha.

Data 19/04/2017.

Voltando a cidade e às tensões centro/ periferia, nos parece pertinente a contribuição do arquiteto italiano Francesco Careri (2013), que se remete à imagem de ilhas e arquipélagos para definir o tensionamento centro e periferia nas cidades. Mas além da imagem, apresentanos a potência dos espaços distantes do centro - muitas vezes tidos como vazios - como lugares em constante transformação. Ele fala de arquipélagos de onde é possível ver, a partir do mergulho imersivo, não somente o mar vazio, mas também aquilo que está submerso: múltiplas identidades que revelam que o aparentemente vazio é repleto de substâncias a serem percebidas. Vejamos as ruas como esse mar, atentos ao que Careri escreve:

No centro, o tempo parou, as transformações congelaram-se e, quando ocorrem, são de tal modo evidentes que não escondem imprevisto algum: desenvolvem-se sob estrita vigilância, sob o vigilante controle da cidade. Encontramos nas margens um certo dinamismo e podemos observar o devir de um organismo vital que se transforma, deixando ao seu redor e no seu interior partes inteiras de território ao abandono e mais dificilmente controláveis. (...) Os espaços vazios que determinam a sua figura são os lugares que, mais do que qualquer outro, representam a nossa civilização no seu devir inconsciente e múltiplo. Essas amnésias urbanas não estão apenas à espera de ser preenchidas de coisas, mas são espaços vivos a ser preenchidos de significados. Portanto, não se trata de uma não cidade a ser transformada em cidade, mas de uma cidade paralela com dinâmicas e estruturas próprias que ainda devem ser compreendidas. (CARERI, 2013, p. 158-159, grifo nosso).

Carlos Fortuna (2018) nos convida a olhar pela diversidade e diverCidade, indicando que todas as caminhadas na cidade podem originar relações inesperadas em público, que vão desde as solidariedades espontâneas até o reconhecimento de desigualdades e racismos. Neste mesmo artigo, o autor falando de caminhada inesperada na cidade sublinha a importância da abordagem etnográfica da qual "retirou inegáveis vantagens, tanto analíticas e interpretativas, como pedagógicas".

Nesse projeto de pesquisa e extensão universitária a abordagem etnográfica está baseada nos encontros e caminhadas compreendidas como espécie de 'técnica do corpo' (MAUSS, 2003) focalizadas a partir da ideia seminal de Erwing Goffman (2009) que considera o mundo um teatro cuja presença dos atores em suas práticas cotidianas, busca forjar uma imagem de si suficientemente convincente para os outros. O processo etnográfico se fez acompanhar de registros fotográficos (BARBOSA, 2016) e suas consequentes devolutivas, realizadas a cada seis meses, seguidas de leitura conjunta e seleção de corpus fotográfico a partir do qual pautas, temas e rumos foram sendo incorporados tanto à pesquisa quanto à produção artística do grupo Oriundo. Parafraseando a antropóloga/ geógrafa Soledad Martinez (2019) começamos perguntando a nossos protagonistas: Podemos andar com vocês? E assim organizamos caminhadas fotográficas no novo bairro Tapera III.

\section{Ato 3: Encontros e caminhadas - Situando a produção imagética do AntropoArte}

A produção e posterior leitura de imagens constitui modo específico de construção do corpus de pesquisa antropológica que permite a abordagem de conhecimentos pautados na representação do mundo sensível e simbólico, que pode permitir uma atenção especial a oralidade, produção de narrativas do grupo estudado (CEZAR, 2014). Essa produção exige do pesquisador um esforço interdisciplinar uma vez quese aproxima docampodasemiótica, linguística e comunicação. Os fenômenos sociais podem assim ser alcançados em sua complexidade e multidimensionalidade, permitindo sua sistematização e, concomitantemente, a expressão 
de outras possíveis demandas, interesses e anseios dos interlocutores a partir de processos dialógicos pautados nas próprias imagens, uma vez que é inerente a essas a capacidade de alusão ao mundo sensível e imaginário (CHAUÍ, 1988).

Ao longo desse projeto de extensão foi proposto também a apropriação do audiovisual enquanto instrumento metodológico de pesquisa, voltado ao registro e representação de momentos importantes do desenvolvimento das atividades do grupo teatral: caminhadas, ensaios, oficinas e performances. Também foram propostas atividades em que a relação entre pesquisadoras e os sujeitos pesquisados acontecessem por meio da utilização de imagens. Interessou nestes processos potencializar as características inerentes ao audiovisual como: a facilidade técnica de realização de filmagens, sua cômoda repetição enquanto processo, a visualização e observação dos resultados obtidos, feita indeferidamente, quantas vezes necessário, o que possibilita o exame repetido das imagens, dando a esse meio certa emancipação em relação à observação direta dos processos sociais (FRANCE, 1998).

Essas características da produção e utilização das imagens (fotografias e vídeos) em antropologia permitiram que a pesquisa paulatinamente fosse adensada num processo por meio do qual o ato de descoberta progressiva do "Outro" passasse não somente a acontecer a partir do "olhar, ouvir e escrever" (OLIVEIRA, 1996) mas, e principalmente, passaram a acontecer a partir da produção, leitura e releitura de seus registros imagéticos (SAMAIN; MENDONÇA, 2000). Para tanto a imagem foi agenciada como: (1) meio de criar e retroalimentar a relação das pesquisadoras com seus interlocutores; (2) meio de evidenciar e colocar em relevo tanto o discurso verbal como as técnicas corporais (olhares, silêncios, expressões faciais e a produção de performances etc.) e demais percepções que ascendem ao mundo visível; (3) meio que induz processos de representação de si tanto para as pesquisadoras como para seus interlocutores; (4) meio do qual as pesquisadoras e seus interlocutores podem se valer para retroalimentar processos de construção de conhecimentos mútuos; (5) meio que permitiu que as pesquisadoras acessassem sentidos que seus interlocutores atribuem às imagens e aos processos de sua produção.

Num segundo momento do projeto de extensão foi privilegiado o uso das imagens no encaminhamento de foto-entrevistas com as mães dos jovens tendo como parâmetros as contribuições de Collier Jr. (1973), Achutti (1997) e Von Simson (2007) e as proposições de Wang e Burris (1997) sobre o Photovoice. A produção e leitura de fotografias potencializa a fala e narrativa sobre experiências e vivências. Reconhecer e oferecer meios para que as vozes dos interlocutores no processo de pesquisa e discussão sejam preponderantes no encaminhamento da construção de material que ofereça e registre o saber, falas, anseios e conflitos relativos aos processos sociais vivenciados nas margens da cidade constituiu tarefa metodológica que fundamenta a execução do projeto.

O trabalho de análise dos vídeos aconteceu por meio de decupagem, roteirização e edição do material resultante como forma de refletir sobre os significados e acessos desiguais dos nossos interlocutores à cidade buscando compartilhar com eles e com outros projetos de antropologia urbana e de educação não-formal os saberes e críticas resultantes desta pesquisa. Se por um lado havia questões de vulnerabilidade ambiental que imprimiam contingências aos modos de vida e visão de mundo desses jovens quando moravam na comunidade da Margem da Linha, o deslocamento da pesquisa e, por conseguinte, da produção imagética e dialógica para o conjunto habitacional do bairro Tapera III nos permitiu compreender outras experiências e contingências de acesso à cidade, mas agora ampliando o escopo de interlocução para as mães e avós dos jovens do grupo teatral Oriundo que tinham sofrido o processo de remoção para o novo bairro.

A construção das imagens foi de fundamental importância pois nos permitiu distinguir a paisagem desses dois distintos espaços urbanos a partir das marcas diacríticas do 
mundo visível, socialmente construídas. Por um lado a favela da Margem da Linha, localizada no Parque Rodoviário, enclave que cruza a estrada vicinal BR 101 na entrada principal da cidade, constituída por uma única rua de paralelepípedo que segue paralela à desativada linha de trem, e que nesse trecho é cercada aos fundos pelo alto muro de bloco de concreto, tendo as grandes e frondosas árvores que servem de refúgio da vizinhança contra o calor do sol escaldante e o campo de futebol em que a meninada se reúne no final do dia. Já as imagens das ruas do bairro da Tapera III revelam o asfalto nivelado que forma um mosaico de diferentes ruas cujas fachadas das casas são protegidas por muros e portões altos, muitos deles não possuem o abrigo de árvores nas calçadas. Ao redor do bairro novo uma grande extensão de mato cerca todo o bairro e, bem ao fundo, se estende no horizonte a silhueta de prédios altos que sabemos estar concentrados nos bairros nobres da cidade que invade, com seus 450 mil habitantes, a planície que margeia o Rio Paraíba do Sul, sendo esta a penúltima cidade a ali depositar seus dejetos antes do derradeiro encontro com o mar.

Foi a partir da produção das imagens que se pode compreender os sinais visuais das marcas que a violência urbana vai imprimindo nesses espaços: construções não terminadas e abandonadas, carros depenados abandonados, símbolos de facções criminosas inscritas em tinta spray concorrem e/ ou buscam ser controladas a partir de inscrições que professam o sagrado. Foi também a partir das caminhadas e das imagens produzidas pelos nossos jovens interlocutores no novo bairro que pudemos compreender os esforços e investimento das famílias para diferenciarem suas casas uma das outras, uma vez que essas tinham sido entregues num padrão único de construção.

A medida que as imagens resultantes da pesquisa foram sendo devolvidas o próprio processo de interlocução foi sendo adensado e novas miradas e abordagens puderam ser propostas e compartilhadas. Assim, as famílias dos jovens foram convidadas a se engajar no processo a partir de entrevistas realizadas por
Caterine com a colaboração das bolsistas da equipe. Foram entrevistadas sete mães/ avós dos jovens interlocutores e, a partir dessas informações foram construídas árvores genealógicas que buscaram mapear a trajetória de vida dessas famílias na cidade, ao longo dos anos.

Figura 6. Construção das árvores genealógicas (fonte: AntropoArte, Caderno digital 06/2019). 


\section{ÁRVORES GENEALÓGICAS}
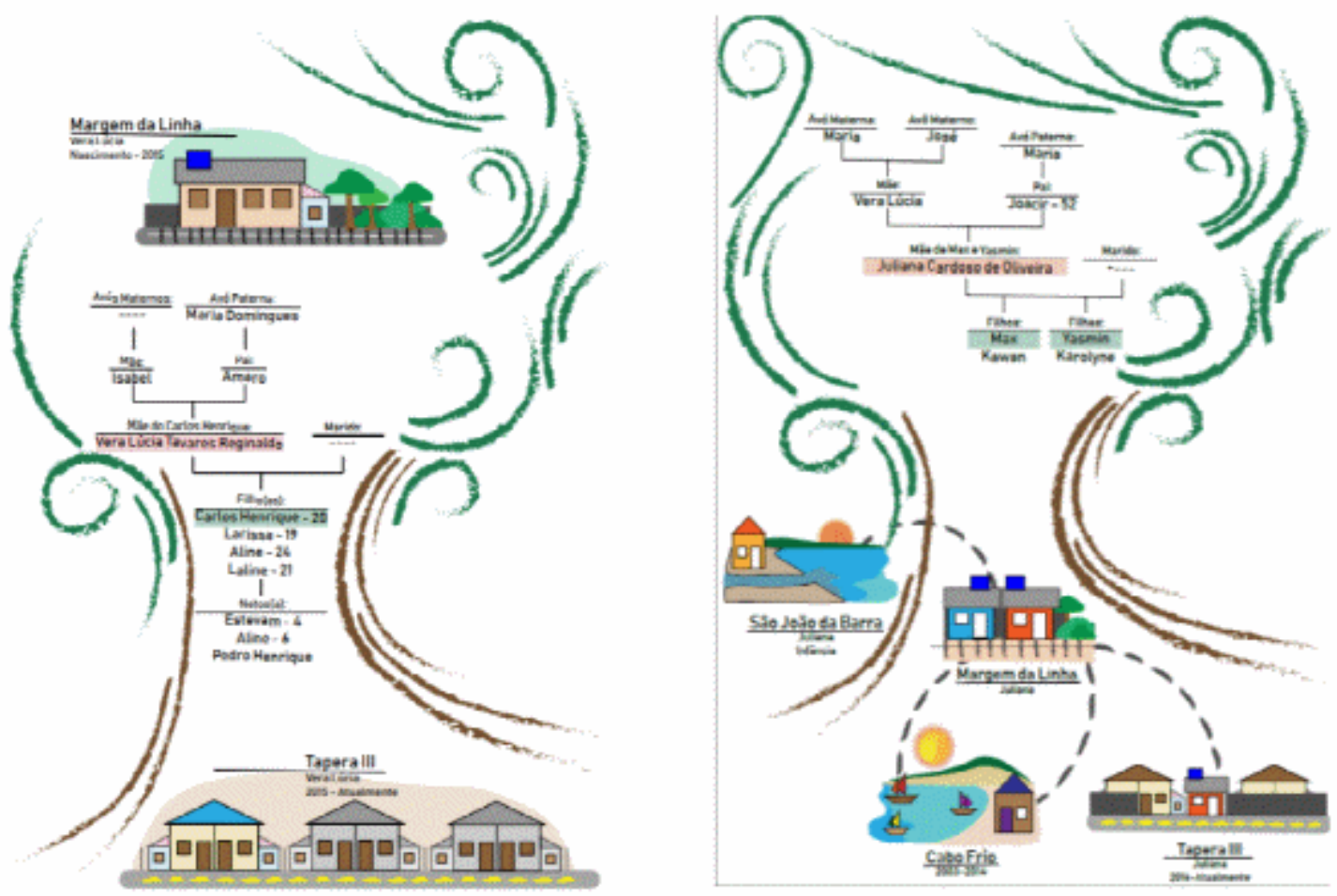

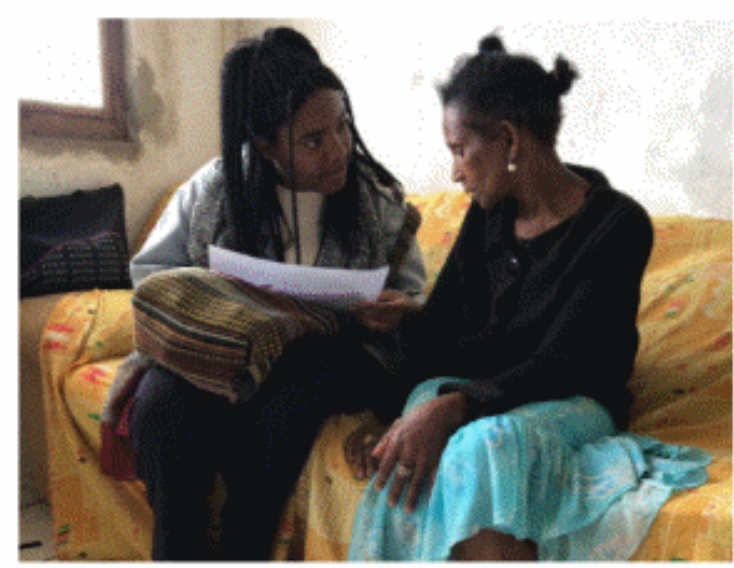

"Sou campista. Morava em lbitioca, de Lá fui para Barra de Itabapoana e de Barra junto com meus filhos para Margem da Linha. Esse era o meu lugar! Só que por causa da prefeita recebi o convite de me retirar e me trouxeram para cá. Que saudade da Margem e da vida que tínhamos lá".

Vera avó de Kaue, 25/08/2018, ex-moradora da Margem da Linha).

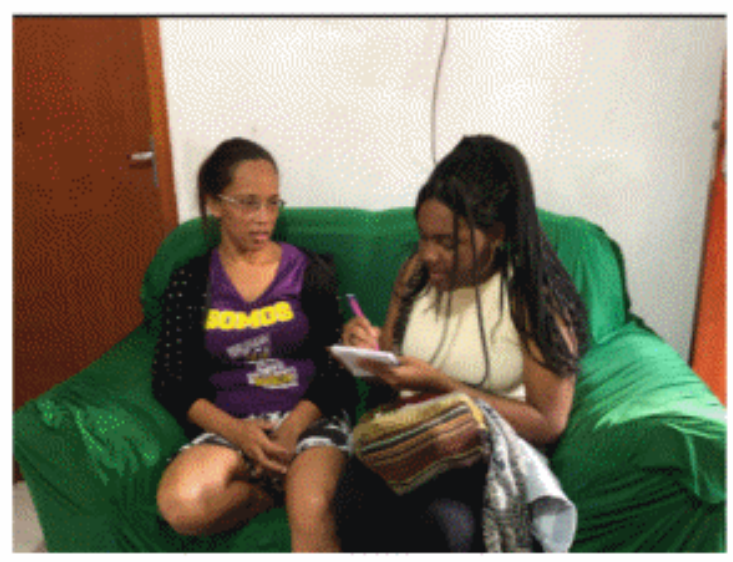

"Eu morava em São João da Barra, vim para Margem aos oito anos de idade. Entre minhas idas e vindas sempre retornei para Linha. Mas, um belo dia tive a decepção de sair da Margem e tive que vir para Ururai. Na Linha eu tinha segurança. $E$ aqui nem convivência. Que saudade daquele lugar que me acolheu. Minha Linha!"

Juliana mãe de Yasmim e Max, data 18/08/2018, ex-moradora da Margem da Linha). 
Ato 4: Construção do filme "Caminhadas e encontros: da Margem da linha a Tapera III"

Tendo duração de 33 minutos, esse é o segundo documentário realizado pelo projeto AntropoArte. O processo de pesquisa e extensão universitária conduzida a partir da produção de imagens gerou, ao longo dos dois anos, um acervo complexo de ser acessado em sua integralidade e diverso em suas potencialidades, o que permitiu que a pesquisadora-diretora convidasse o cineasta Maxence Loyer, jovem francês, instalado no Rio de Janeiro, para conhecer o material fílmico por ela decupado e pré-roteirizado. Maxence também teve acesso às fotografias, mapas, árvores genealógicas, filmagens das performances do grupo Oriundo, materiais resultantes do projeto que poderiam ser alinhavados às representações fílmicas. A partir daí foi iniciado um processo de roteirização conjunta e produção de novas imagens externas da Margem da Linha e da Tapera III, que permitiram realizar a representação e distinção estética dessas diferentes paisagens, fundamentais para a construção da narrativa fílmica.

A análise do filme que apresentamos, de fato não segue uma rígida metodologia, mas parte da seleção e descrição de fragmentos do documentário, seguindo a própria orientação sequencial de aparição na estrutura do filme. Nossa intenção é abordar a análise como uma espécie de relato (PENAFRIA, 2009), buscando destacar e explicitar algumas das intenções, sensações e significados reportados à tais imagens compondo um mosaico produzido por Atos que aqui buscamos sistematizar.

Os encontros e caminhadas, partes constituintes dessa pesquisa de extensão, produziram diálogos e imagens fotográficas que por sua vez foram tematizados e provocaram abertura para a uma exposição fotográfica conjugada a performance cênica apresentada pelo Oriundo. Durante esse momento de mostra e devolutiva das imagens foram fomentados diálogos em que os moradores puderam participar e interagir da própria exposição e performance, sendo que tais informações permitiram a produção de um Mapa Falado da comunidade da Margem da Linha.

A etnografia feita a partir dos momentos de encontro dos jovens durante as atividades desenvolvidas no cotidiano do grupo teatral Oriundo junto ao Centro Juvenil São Pedro nos permitiram compreender, ao longo do tempo das oficinas e ensaio das performances, as estratégias e protagonismos agenciados pelos interlocutores que lhes permitiram transformar seu pedaço (MAGNANI, 1984) em um lugar na cidade. Esse processo culminou na performance "Olhares de jovens sobre um lugar chamado a Margem da Linha" apresentada na Casa de Cultura Villa Maria no dia 25 de abril de 2018. Nela o cotidiano da comunidade e os elementos que marcam as percepções dos integrantes do grupo Oriundo acerca do seu local de convívio foram performadas a partir da transcodificação dos tipos de plantas, da rua, da linha de trem ali presentes em expressões corporais incorporadas pelos integrantes do grupo. Já a performance "Encontros" narra a história dos moradores da Margem da Linha que tiveram suas casas demolidas e foram obrigados a passar a viver no Conjunto Habitacional "Morar Feliz", também denominado de Tapera III, em Ururaí. Por meio da performance os jovens relatam a sua história entre a Margem da Linha, as formas de convivência, frustrações e consequente desilusões vindas com a nova moradia.

O filme Caminhadas e encontros: da Margem da linha a Tapera III oferece ao espectador uma representação estética e imagética dessas duas distintas comunidades, abordando o processo de realocação de moradores a partir de narrativas sobre o ponto de vista de jovens e seus familiares, e da representação de tais visões de mundo por meio de fotografias e da produção cinematográfica dialogada. A primeira interlocutora que nos é apresentada no filme é a jovem Yasmin, que escolheu fotografar a casa da sua avó onde morou enquanto a sua própria casa estava sendo construída. Em seguida Carlos Henrique descreve que gosta muito da casa em que habita. Ketleny tirou fotos de sua casa e do descampado presente em sua nova vizinhança, 
recordando que brincava de queimado na rua quando morava na Margem da Linha, coisa que não acontece mais depois da mudança para sua nova casa, na Tapera III.

Kauê descreve o falecimento de seu pai e escolhe fotografar instalações elétricas, em referência ao acidente sofrido por seu pai que faleceu ao tentar solucionar problemas da rede elétrica e se distraiu com uma briga entre vizinhos. Também fotografa a igreja da comunidade onde seu pai foi velado e a casa de seu avô onde mora atualmente. Bethânia escolheu fotografar a açaiteria, localizada próxima a sua casa, muito frequentada por ela e os amigos. Udson afirma não gostar muito do local e escolheu fotografar pessoas conhecidas ao sol com objetivo de denunciar e, assim, reclamar a falta de arborização do novo bairro. $\mathrm{O}$ jovem também fotografa a fachada de sua casa como única parte que gosta no conjunto habitacional. Francisco fotografou o mato localizado ao redor de onde morava afirmando sentir saudade da infância e do campo de futebol.

Esse primeiro recurso narrativo construído a partir da leitura e sistematização da apresentação de fotografias produzidas pelos jovens interlocutores da pesquisa e participantes do grupo teatral Oriundo é articulado com as narrativas de suas mães e/ou avós, entrevistadas em suas casas e dão conta de trajetórias familiares que, ao longo de 30, por vezes 40 anos, viveram em suas respectivas casas, localizadas na favela da Margem da Linha. Suas falas abordam o processo de desapropriação e remoção ocorrido há 4 anos quando suas famílias passaram a viver no bairro da Tapera III. Em comum nas falas o descontentamento em morar no novo bairro em razão da falta de equipamentos de saúde, lazer, segurança pública, transporte regular, falta de comércio com preços acessíveis e variedade de produtos. Essa experiência é tributária da comparação direta feita pelos nossos interlocutores em relação às condições de moradia que tinham acesso quando moravam na Margem da Linha, em decorrência da proximidade do shopping e de grandes supermercados localizados em suas imediações. Outra reclamação diz respeito ao isolamento do novo bairro que o tornou espaço de ação de facções criminosas, sendo por isso mesmo marcado pela violência urbana. A grande preocupação das mães é com a segurança de seus filhos e filhas.

As contradições relativas ao processo de realocação dessas famílias desde sua residência na Margem da Linha para uma outra casa construída nesse conjunto habitacional são narradas de forma lacunar. Mas a insatisfação diante do processo de realocação e do local das novas residências são comuns às entrevistadas. Das sete entrevistas realizadas com mães/avós somente uma das entrevistadas disse estar feliz com a casa mas, ainda assim, admite que sente falta de sua antiga casa na Margem da Linha devido ao fato dessa ter sido perto de tudo e ali ter muitos espaços seguros para as brincadeiras das crianças, coisa que diz não acontecer no bairro Tapera III.

O descontentamento patente nas falas das entrevistadas diz respeito às atitudes do poder público no processo de cadastro das famílias que agiu de maneira muitas vezes impositiva, sem permitir margem de resistência no momento da realização da mudança que foi feita em bloco, orquestrada à demolição consecutiva das casas desocupadas, o que deixou em situação de desalento e vulnerabilidade as famílias que decidiram não participar da realocação, impondo a mudança pela força da sensação de abandono e insegurança diante da possibilidade da perda dos vizinhos mais próximos, muitas vezes parentes, com dezenas de anos de convivência e compartilhamento de vida e de criação dos filhos.

Outro questionamento constante é sobre a justificativa para a realocação das famílias uma vez que segundo as entrevistadas, o poder público poderia ter realizado com menos soma de dinheiro, os investimentos necessários em saneamento básico, esgoto e limpeza dos bueiros para que as residências da Margem da Linha fossem respeitadas em sua integralidade, estética, tamanho, disposição espacial, composição dos quintais e respeito às relações de vizinhança, coisa 
que não aconteceu nem no processo de retirada nem a partir da realocação dessas famílias. Para poder abordar a complexidade das narrativas das situações vivenciadas pelos nossos interlocutores se elaborou o planejamento e solução gráfica de construção de árvores genealógicas de cada uma das famílias tendo como ponto focal destacado tanto os jovens como suas respectivas mães/ avós entrevistadas. Nessas árvores construiu-se também as referências espaciais das trajetórias de moradia de cada família até sua chegada na Tapera III.

\section{Ato 5: Produção audiovisual - pesquisa, extensão universitária e educação não-formal}

As ações de pesquisa e devolutivas do projeto de extensão acontecem junto à comunidade local e acadêmica, divulgados em forma de folders, grafites, caderno digital e filmes que visam fornecer meios para o intercâmbio de conhecimentos e práticas antropológicas e artísticas construídas a partir de experiências que mergulham no cotidiano de produção artística de um grupo de teatro que congrega jovens negros e pobres, moradores de comunidades da cidade. Essas ações são importantes pois permitem dar visibilidade às experiências que já aconteciam em situações distantes da vida universitária, produzidas junto a um projeto de educação nãoformal que privilegia o teatro como linguagem, e que pautam a história e cultura afro-brasileira em meio ao debate de temas pungentes para o cotidiano desses jovens, como o seu acesso à cidade onde moram.

A caminhada e as consequentes atividades de visualização, leitura e seleção conjunta das fotografias resultantes, permitiram que narrativas sobre diferentes significados e aspectos de se habitar na Margem da Linha fossem compartilhados. Também chamou a atenção o fato de alguns jovens se remeterem a experiência de não mais morar ali, por suas famílias terem sido removidas para outro bairro, o que os levou a comparar memórias de sua vida na antiga vizinhança em relação a nova casa, todas localizadas no projeto habitacional "Morar
Feliz", localizado no distante bairro denominado de Tapera III.

As ações de educação não-formal oferecem maior liberdade aos professores, que agem como mediadores de aprendizagem, abordando conteúdos extracurriculares, o que equivale dizer que esses não são historicamente sistematizados num currículo, distribuídos em disciplinas, divididas por idade e nível de conhecimento, ministrados seriada e sequencialmente visando, ao final da formação, conferir um reconhecido grau de titulação ao educando. A educação não-formal, assim com a informal ou incidental, lida com educandos de todas as idades e fases da vida e pode proporcionar ações educativas pautadas em conhecimentos críticos sobre o mundo envolvente relacionando indivíduos, culturas, relações sociais, contingências e relações de poder às quais estão submetidos. Também pode pautar temáticas prementes para diferentes fases da vida como os processos de construção identitárias e os conflitos deles resultantes. Compreender as especificidades desse projeto de pesquisa, sua articulação com processos de educação não-formal e agenciamento dos resultantes produtos audiovisuais por parte dos interlocutores nos permitiu questionar o próprio papel da antropologia, seja como metodologia importante para o desenvolvimento de ações de extensão universitária, seja enquanto disciplina crítica que poderia não somente estar presente na formação de professores, mas nas mais variadas ações desenvolvidas na área de educação.

\section{Referências bibliográficas}

ACHUTTI, Luiz. Fotoetnografia: um estudo de antropologia visual sobre cotidiano, lixo e trabalho. Porto Alegre: Tomo editorial; Palmarinca, 1997.

BARBOSA, Andréa; NOVAES, Sylvia Caiuby; CUNHA, Edgar Teodoro da; HIKIJI, Rose Satiko Gitirana. A Experiência da Imagem na Etnografia. São Paulo: Terceiro Nome, 2016.

BRASIL, "Atlas da Violência - 2016" In: Nota 
Técnica n. 17. Brasília: Instituto de Pesquisa Econômica Aplicada; Fórum Brasileiro de Segurança Pública, 2016. p. 55.

CARERI, Francesco. Walkscapes: o caminhar como prática estética. São Paulo: Editora GG Brasil, 2013.

CERTEAU, Michel. A invenção do cotidiano: artes de fazer. Petrópolis, RJ: Vozes, 1994.

CEZAR, Lilian Sagio. "O estatuto da fotografia e a pesquisa etnográfica: direito de uso de imagem e representação autorizada”. In: Ana Lúcia Camargo Ferraz; João Martinho de Mendonça. (Org.). Antropologia visual: perspectivas de ensino e pesquisa. Brasília: ABA, 2014. p. 505-532.

CHAUÍ, Marilena. "Janela da alma, espelho do mundo". In: NOVAES. Adauto (org.). O Olhar. São Paulo. São Paulo: Companhia das Letras, 1988. p. 31-64.

COLLIER JR., John. Antropologia visual: A fotografia como método de pesquisa. São Paulo. Editora da Universidade de São Paulo, 1973.

FAVRET-SAADA. "Ser Afetado". In: Cadernos de Campo - Revista dos alunos de Pós-Graduação em Antropologia Social da USP. Ano 14, N. 13, p. 155-163, 2005.

FORTUNA, Carlos. "A Pós-Verdade e a Guarda do Rebanho". In Sociologia Online - Revista da Associação Portuguesa de Sociologia, n. 18, 2018.

JACQUES, Paola Berenstein. Estética da ginga: a arquitetura das favelas através da obra de Hélio Oiticica. Rio de Janeiro: Casa da Palavra, 2003.

LEMINSKI, Paulo. La vie en close. São Paulo: Brasiliense, 1991.

GOFFMAN, Erving. A representação do eu na vida cotidiana. Petrópolis, RJ: Editora Vozes, 2009.
MARTINEZ, Soledad. May I Walk with You? Exploring Urban Inequality in Everyday Walking Practices in Santiago de Chile. Londres: University College London, 2019.

MAGNANI, José Guilherme Cantor. Festa no pedaço: Cultura Popular e Lazer na Cidade. São Paulo: Brasiliense, 1984.

MATIAS, Glauber Rabelo. Palco e Resistência: a geração do Teatro de Bolso e as suas lutas por hegemonia nos anos de $1980 \mathrm{em}$ Campos dos Goytacazes/RJ. 241 f. Tese (Doutorado em Sociologia Política) - Centro de Ciências do Homem, UENF, Campos dos Goytacazes, 2016.

MAUSS, Marcel. Sociologia e Antropologia. São Paulo: Cosac Naify, 2003.

OLIVEIRA, Roberto Cardoso. O trabalho do antropólogo: Olhar, ouvir, escrever. São Paulo, Ed. Unesp. 1998a.

PENAFRIA, Manuela. "Análise de Filmes Conceito e metodologia (s)". In: VI Congresso SOPCOM, Lisboa, 2009.

RANCIÈRE, Jacques. A Partilha do Sensível: Estética e Política. São Paulo: Editora 34, 2005.

REGINENSI, Caterine. "AntropoArte: Um projeto de extensão e a construção de pesquisas etnográficas”. In: Áltera, v.2, n.9: p. 182-200. 2019.

“AntropoArte", Caderno Digital, 2019. (Link: https://issuu.com/caterinereginensi/docs/ teste vs12)

SAMAIN, Etienne; MENDONÇA, João $M$. de. "Entre a escrita e a imagem: Diálogos com Roberto Cardoso de Oliveira”. In: Revista de Antropologia. São Paulo, USP, 2000, V. 43 nº 1.

VON SIMSON, Olga. Carnaval em Branco e Negro: Carnaval Popular Paulistano: 1914-1988. Campinas: Ed. Unicamp; São Paulo: Edusp, 2007. 
WANG, Caroline; BURRIS, Mary Ann. (1997).

"Photovoice: concept, methodology, and use for participatory needs assessment". In: Health

Education \& Behavior, V. 24, N. 3, p. 369-387.

13 Para uma análise da coleção de Theon Spanudis, cf. Ribeiro (2001). 